\title{
Non-Traditional Motherhood in Contemporary Irish Film: Carmel Winters' Feature Film Snap (2010) and Her Short Film Limbo (2008)
}

\begin{abstract}
Kira J. Collins"
This article will further develop E. Ann Kaplan's originally American categorisation of motherhood in media in order to outline two important maternal categories in contemporary Irish film: the woman who wants to be a mother and the regretting mother. In the last chapter of her book Motherhood and Representation Kaplan defines six maternal categories. According to her, these serve as a "basis for later researchers to argue from."1 To further develop this foundation in an Irish context, a textual analysis of Carmel Winters' films Limbo, $^{2}$ and Snap ${ }^{3}$ will serve as a starting point in this article. Winters' complex female characters offer an especially valuable example of maternal representations in Irish film. The analysis will show how the woman who wants to be a mother in Limbo and the regretting mother of Snap need a more defined description of motherhood in film than Kaplan's categorisation offers. The woman who wants to be a mother in Limbo is positioned in a liminal space between old and new values, negotiating her maternal identity during a time of economic change in Ireland. A victim of sexual abuse, the regretting mother in Snap is unable to tolerate emotional or physical closeness, which is represented on screen through close-ups of hands. Society, however, blames the mother for the ills of her son who must also deal with the sexual abuse by his grandfather. The newly developed categories of the regretting mother and the woman who wants to be a mother show the necessity to adapt Kaplan's American categorisation to an Irish film context.
\end{abstract}

\section{Introduction}

While the Irish mother has always been a stock character of Irish cinema, contemporary Irish film offers surprisingly complex maternal characters such as the woman who wants to be a mother in Carmel Winters' short film Limbo (2008) and the regretting mother in her feature film Snap (2010). The textual analysis of these non-traditional maternal characters will show that it is necessary to further develop E. Ann Kaplan's categorisation of motherhood in American media in

*PhD Candidate, Maynooth University, Ireland.

1. E. Ann Kaplan, Motherhood and Representation: The Mother in Popular Culture and Melodrama (London: Routledge, 1992), 180.

2. Carmel Winters, Limbo, Film, 2008.

3. Winters, Snap, Film, 2010. 
order to suit an Irish contemporary context. As her book Motherhood and Representation was published in 1992 and refers to the developments in the 1980s, Kaplan merely outlined maternal discourses that developed during this time, indicating that her categorisation serves as a "basis for later researchers to argue from."4 Nevertheless, while limited, her research offers an incredibly rare and valuable account of maternal representations in contemporary film and can, therefore, not entirely be dismissed. Adjusting the categorisation to an Irish context, the complex maternal characters in Winters' films offer an especially valuable starting point from which Kaplan's definition can be further developed. Building on Kaplan's groundwork, scholarship from such feminist researchers as Clare O'Hagan, Rozsika Parker and Orna Donath will be applied to both films in order to understand the representation of Winters' complex maternal characters.

This article will firstly introduce the reader to Irish cinema in order to situate Winters' films in their wider context. It next outlines Kaplan's unique approach to categorising representations of motherhood, focusing in particular on the two categories that are most relevant for the films under discussion: the working mother and the absent mother. This introductory work will show that Limbo portrays a maternal character outside of Kaplan's categorisation that still has to be defined within the theory: the woman who wants to be a mother. While the maternal character in Snap incorporates aspects of the absent, working mother of Kaplan's categorisation, a more nuanced category is necessary to fully define the regretting mother's representation in Winters' film.

\section{Irish Film}

Since the 1990s, Irish cinema has become more transnational as tax incentives have lured international film companies into Ireland, supporting more mainstream film productions than in prior years. Increased international finance has also, however, brought a representational disadvantage as Martin McLoone states:

The danger is that, to attract financial support, such films propose a view of Ireland that is already familiar to international funders and which funders in turn believe audiences are likely to recognise and identify with. ${ }^{5}$

Such representations in mainstream Irish film include the Irish Mammy who is situated within the domestic sphere and closely linked to Irish nationalism as well as the Catholic Church.

4. Kaplan, Motherhood and Representation, 180.

5. Martin McLoone, Irish Film. The Emergence of Contemporary Cinema (London: British Film Institute, 2000), 114. 
While filmmaking in the Celtic Tiger period (mid-1990s to late 2000s) widely glosses over societal issues, focusing on representations of the middle-class, independent film productions still highlight working-class women and their struggles. It is important to note that these independent films are rather genredriven in a European comparison and still highly influenced by American film, offering a solid basis to apply Kaplan's American categorisation. Nevertheless, these Irish, more indigenous productions offer a stage for culturally marginalised voices such as the non-traditional, regretting mother of Snap. Exploring the downside of the Celtic Tiger era and the disadvantaged members of Irish society, these independent films exist through television subsidies and the possibility to increase their audience by broadcasting not just in theatres but also on national television. ${ }^{6}$

Beside the feature film, the short film was and is an important medium in Irish film production. Especially during the years when the Irish Film Board was suspended, short films still offered an alternative, low-budget way of filmmaking. In Winters' short film Limbo, she is able to represent a character that is subsumed by her wish to mother, yet is seemingly physically not able to. As will be discussed below, the format of the short allows Winters' to represent this challenging depiction of motherhood for a national audience that is able to contextualise the narrative. Short films often reveal themselves as stepping stones for emerging artists and allow engagement with more radical ideas. "This is true, also for feminist cinema in general and even for the ability of women directors to break through into film-making at all."7 This trend is reflected in Winters' filmic career that started with the short film Limbo as well as the fact that both of her films allow marginalised voices of non-traditional mothers to emerge.

\section{E. Ann Kaplan's Categorisation of Motherhood}

In the final chapter of her book Motherhood and Representation Kaplan identifies six types of mothers who tend to emerge in American media in the 1980s: the Absent Mother, the Working Mother, the Abusive Mother, the Lesbian Mother, the Woman-Who-Refuses-To-Mother and the Self-Fulfilled Mother. These types are not always independent of each other and can be interwoven within their representation of the maternal character. Kaplan builds her categorisation on "data accumulated from representations in popular materials - in films and novels, but also in television programs, news articles, advertisements and

6. Ibid., Irish Film, 115; Ruth Barton, Irish National Cinema (London and New York: Routledge, 2004), 109, 186; Michael Patrick Gillespie, The Myth of an Irish Cinema Approaching Irish-Themed Films (Syracuse, New York: Syracuse University Press, 2008), $55,72$.

7. McLoone, Irish Film, 160. 
women's magazines." ${ }^{8}$ Two of the representations will be important for the analysis of Limbo and Snap - the working mother, and the absent mother. Therefore, while acknowledging the importance within film and media studies of Kaplan's insights into the diversity of maternal representations beyond traditional motherhood, this article will reconfigure these categories to address the newly emerging maternal representations in contemporary Irish film.

According to Kaplan, the working mother is represented as a single or married woman, and as a consequence, the cases of single motherhood exceed those of single fatherhood. In the 1980s, fear over diminishing traditional gender roles were part of the discourse about the working mother, highlighting the possible positive and negative effects on female children in particular. As a result, the desirability of the domestic role for women was highlighted in American maternal representations, underlining woman's ability to choose between working and stay-at-home motherhood. At the same time, articles in prominent publications such as the New York Times, discussed the difficulties working women had in being valued in the work place after having a child. ${ }^{9}$

The representation of the "Executive Mom" was criticised by American print media - such as the Wall Street Journal - as it misrepresents the task of combining work and motherhood as fairly easy, not acknowledging the difficulties mothers face in combining the two jobs. The depiction of beautiful - but not sexually attractive - mothers with happy babies encourages women to follow an ideal that, even though it looks effortless, requires hard work. The fact that the mother is represented as beautiful but not sexy, confirms Kaplan's finding that motherhood, work and sex are almost never combined in the maternal representation. Mothers either work or are able to be sexually active but not both. ${ }^{10}$ In contrast to the representation of the beautiful executive mother, the executive father is represented as powerful and sexy man. ${ }^{11}$

Like the "Executive Mom," the "Super-Mom" is a working mother. But instead of equally focusing on career and motherhood, the Super-Mom concentrates on the development of her child by offering him or her the best education and nutrition. Her whole life is subsumed by the needs of the child. Films like Baby Boom ${ }^{12}$ depict a satirical turn on the Super-Mom. Diane Keaton's character needs to give up her old ambitions in the city in order to find domestic bliss in the country side, ensuring a nuclear family setting and a small business instead of her old, demanding executive job..$^{13}$

8. Kaplan, Motherhood and Representation, 180.

9. Ibid., 188.

10. Kaplan, "Sex, Work and Motherhood: The Impossible Triangle," The Journal of Sex Research 27, no. 3 (1990), 409-425.

11. Kaplan, Motherhood and Representation, 188.

12. Charles Shyer, Baby Boom, Film, 1987.

13. Kaplan, Motherhood and Representation, 188. 
The absent mother presupposes a nurturing father as in the recent American sitcom Baby Daddy. ${ }^{14}$ He will be forced into the role of lone fatherhood by the departure (or sometimes death) of the mother and, as the protagonist of the story, will gain the sympathy of the audience. The mother, however, will later regret her maternal absence. This representational focus on the father mirrors the emerging recognition of parental care in American society during the 1980s. "[B]y 1988, Father's Day ads were as pervasive as Mother's Day ones, and featured more images of the Father holding a baby, sometimes with a daughter by his side, than had even been seen before." ${ }^{15}$ As in Full House, ${ }^{16}$ the absent mother and nurturing father are mostly portrayed within the genre of comedy, offering a light-hearted way to explore new structures of family settings. ${ }^{17}$

\section{The Woman Who Wants to Be a Mother - Limbo}

In 2008, Dublin's Darklight film festival challenged Irish filmmakers to produce a short film in the city in one day. In response, thirty filmmakers created an omnibus film that was edited by Lenny Abrahamson and Declan Lynch. ${ }^{18}$ One of these shorts is the six-minute long film Limbo, written and directed by Carmel Winters. The film portrays an afternoon in the life of a woman who tries to create the illusion of being pregnant. After buying a whole chicken from a butcher, she oils and powders it in a public toilet before strapping it around her belly. Now appearing pregnant, the woman walks to St. Stephen's Green park. Being fascinated by something in the pond, she walks into the water, finding a nappy pin while playing with the algae that surround her.

In his article "The Short Film in Irish Cinema," Conn Holohan proposes a differentiation between short film and feature film similar to the difference between short story and novel. Both stay in relation to each other, yet offer varying technical approaches. While the feature film is able to portray a variety of narrative strands that are representative of a wider reality, the short film is often limited to a singular narrative which transforms reality and is in need of an audience who is able to place this reality back into its historical context. ${ }^{19}$ Therefore, in keeping with Holohan, the audience of Limbo must be familiar with the reality of Ireland in 2008 in order to understand the deeper meaning of its metaphorical statement.

14. Dan Berendsen, Baby Daddy, TV Series, 2012-2017.

15. Kaplan, Motherhood and Representation, 184.

16. Jeff Franklin, Full House, TV Series, 1987-1995.

17. Kaplan, Motherhood and Representation, 184.

18. Dublin: 4DayMovie 2008. Retrieved from https://4daymovie.wordpress.com (accessed: March 2018).

19. Conn Holohan, "The Short Film and Irish Cinema," Estudio Irlandeses 4 (2009), 184. 
In 2008, Ireland went into recession after a decade of unprecedented economic growth that was widely called the Celtic Tiger. Films set within the city during the Celtic Tiger era offered alternative representations outside of the nuclear family, such as lesbian motherhood in Goldfish Memory ${ }^{20}$ and attributed female protagonists a liberal sexuality. However, during the recession, films responded to the emerging anxieties over these more liberal lifestyles. Limbo was one of the first manifestations in Irish cinema of those anxieties, which Rosa González-Casademont has argued in relation to 2008. The year "revealed not only the dire economic impact of the crash but also the repercussions of having discarded old certainties and cultural codes in the rushed process of modernization."21 The representation of the maternal protagonist of Limbo renegotiates stereotypical female roles in an urban setting, mirroring these anxieties.

By doing so, Irish film partially stands in line with the anxieties Kaplan describes in regards to the working woman in the 1980s in America. Fears over the loss of maternal care in society in order to facilitate women's career ambitions led to a reinforcement of female representations that highlight a maternal identity. In Limbo, the woman's wish to be a mother structures the short film's narrative and her identity is solely described as maternal. While the woman's employment status is not disclosed, the setting of urban Ireland just after the Celtic Tiger era positions her within this interpretation. While American film brings the domestic sphere into focus, Limbo negotiates the wish to mother within an urban setting, creating tension between the private and the public.

Limbo's opening sequence offers a visual metaphor for this tension. The audience is presented with a sign of a baby changing room, which shows a person taking care of a small child. The public area of the baby changing room becomes a secretive place for the woman who wants to be a mother in which she can act out her maternal dreams without judgement, oiling and powdering the dead chicken and strapping it close to her body. The baby changing room, therefore, symbolises a liminal space that introduces the private into the public. By doing so, the short film simultaneously introduces the idea of bringing Irish, historically rural, family values into the space of the city and causes the protagonist to focus on her maternal identity instead of work or sexuality.

Also, the public space of the park, to which she walks later, offers a private environment for the woman. Seemingly being the only visitor of the park during the rain, the woman stops at the pond, recognising something shiny in it. Without undressing, the woman walks into the pond to retrieve the shiny object. A closeup shot reveals it to be a nappy pin tangled in algae. After attaching the pin to her

20. Elizabeth Gill, Goldfish Memory, Film, 2003.

21. Rosa González-Casademont, "Representation of Family Tropes and Discourses in Contemporary Irish-Themed Cinema," in Family and Dysfunction in Contemporary Irish Narrative and Film, ed. Marisol Morales-Ladrón (Bern: Peter Lang, 2016), 276. 
own dress, she starts to play with the weed in the pond. These visuals are accompanied by a mixture of fairy tale and lullaby-like sounds that hint at a stereotypical femininity attached to the maternal. At the same time, however, the woman's actions are turned into a grotesque representation of this stereotypical femininity, allowing the audience to question whether motherhood is ultimately desirable. Limbo's protagonist, again, explores her maternal identity in a liminal space that introduces the private into the urban, public sphere and, therefore, symbolically to urban female identities that had tended to be represented in connection to sexuality instead of motherhood in the previous decade. The grotesque aspects of the representation of the woman who wants to be a mother, such as the dead chicken or the lullaby-like sounds, question the desirably and possibility for urban women to turn back to old values.

In this scene, a low camera angle and her willingness to walk into the pond and later barefoot connects the woman's maternal identity to nature. It hints at the patriarchal understanding of women as mothers as a result of their instincts that the feminist sociologist Nancy Chodorow questions. ${ }^{22}$ The grotesque representational aspects of the film reveal that also Limbo questions a naturally given wish to mother. On the one hand, the film questions a traditional understanding of the idea that the right place of woman is motherhood. On the other hand, it allows for a renegotiation of motherhood in the city centre. The representation, however, reduces the woman's ability to mother to a mere possibility as she is not represented with a real baby. The dead chicken, as substitute child, functions as manifestation of the possibilities that lie in the idea of returning to a traditional female role for women living in Dublin, after enthusiasm to access wider opportunities introduced by the economic boom was crushed.

The camerawork in Limbo supports this negotiation by being placed at the height of the woman's belly. On one hand, this reduces her further to her reproductive abilities. On the other hand, in association with the dead chicken, it detaches her from mere motherhood. The linkage between the dead object and the idea of life-giving reproduction indicates infertility and/or the possibility of a previously lost child. Therefore, the camera angle introduces another layer to the short's interpretation that, in combination with the urban setting, underlines the maternal inadequacy of urban women and their need to re-explore motherhood.

The urban woman's positioning in a liminal space between the private and the public as well as motherhood and non-motherhood is addressed by the short films title, Limbo. In the Catholic belief limbo represents a liminal space between heaven and hell. It is rather close to hell but not quite as bad. Here, the woman's possible infertility and longing for motherhood at the start of the recession in Ireland signifies an age of transitioning between new and old values, re-

22. Nancy J. Chodorow, The Reproduction of Mothering (Los Angeles: University of California Press, 1978), 13. 
negotiating ones priorities. With the decline of the influence of the Catholic Church in Ireland, the family is no longer positioned between virtue and $\sin .^{23}$ However, traditional notions are still embedded as in the representation of the woman who wants to be a mother in Limbo. Especially the representation of her wish to mother without a man is reminiscent of the idealised virgin birth that the Catholic Church celebrates, and detaches the modern, urban woman in Limbo from her own sexuality. Therefore, also the dead chicken becomes a liminal object that bridges her wish to mother and her empty womb, positioning her in limbo, awaiting an immaculate pregnancy. The atmosphere of death that surrounds the woman's pseudopregnancy highlights her emotional place close to hell in a grotesque version of a virgin birth.

As described, the narrative of Limbo merely introduces the female protagonist through her wish for motherhood. The woman is therefore given a maternal identity despite the fact that she is most likely not a mother. Winters' film depicts an ambiguous maternal representation that allows for multiple interpretations, incorporating elements of the tragic and the grotesque. The woman's representation as maternal without having a child, as well as the reference to the idea of motherhood as a natural state for women that is questioned by the film, highlights the return to a patriarchal imaginary in Irish cinema. Kaplan's maternal categorisation does not include a woman who wants to be a mother as it merely outlines the representation of women who are already pregnant or having children. The Irish short film, therefore, introduces an important new categorisation that is vital within an Irish film context at the start of the recession in 2008, communicating a renegotiation of traditional gender roles.

\section{The Regretting Mother - Snap}

Snap is a psychological drama that is directed and written by Carmel Winters. Flashbacks tell the story of Stephen (Stephen Moran) who kidnaps a toddler, Adam (Adam Duggan), from a public park and brings him back to his grandfather's (Pascal Scott) house, which is temporarily empty while his grandfather is in hospital. There he takes care of the child, bathing and feeding him, but at the same time feels increasingly overwhelmed by the experience. Through the interaction with the child, Stephen re-enacts his own childhood memories and reappraises his traumatic past. When his mother Sandra (Aisling O'Sullivan) figures out that Stephen is keeping a child hostage at her father's house, she informs the police and takes all the blame. However, Stephen admits to the crime shortly thereafter. Three years later, in the film's present moment, Sandra participates in a documentary to set the record straight about the events

23. González-Casademont, "Representation of Family Tropes, 290. 
and to tell her side of the story. Through the montage of present and past footage ${ }^{24}$ the film slowly unfolds the family's trauma of sexual assault by the grandfather that motivates both Sandra's and Stephen's behaviour.

Snap portrays a maternal character who stages the conflict between maternal ideals and reality. While this article highlights the unique contextual elements of a very specific case of regretting motherhood in Irish cinema, the emergence of the regretting mother is generally visible in European cinema. While maternal regret is portrayed in a variety of contemporary Irish films, such as Glassland from 2015 by Gerard Barrett ${ }^{25}$ and Mammal from 2016 by Rebecca Daly, ${ }^{26}$ Snap offers one of the clearest recent example of a regretting mother in Irish cinema and attributes a lead role to the maternal figure. With these films, contemporary Irish cinema negotiates the depiction of the "bad" mother, while combining parts of Kaplan's maternal categorisation with new representational aspects. These Irish films contrast to the films Kaplan discusses especially in class terms. While Kaplan's grouping is based on white, middle-class mothers who benefit from a certain financial security, the Irish films portray regretting mothers from working-class backgrounds.

In contrast to Kaplan's working mother, Sandra's job does not seem too important to her, and instead functions as a financial necessity for the singleparent household. While she is indeed a working mother who gives her child into the care of her father, she does not pursue a career. Therefore, the sub-categories of the Executive Mom and Super-Mom do not apply to her because Snap clearly portrays the mother's hardship in combining motherhood and work. As this article will show, Sandra's absence due to her work commitments is one of the reasons she supposedly failed as a mother, misjudging the quality of care her father was able to give to her son. Therefore, the category of the absent mother will be explored further in conjunction with the role of the father later in this article.

Furthermore, the representation of work as a threat to the child stays in line with Kaplan's description of the fear of changing gender roles and can be understood, like the wish for motherhood in Limbo, as a re-negotiation of the domestic sphere during the Irish recession. As described in Limbo, also Clare

24. The cinematographer Kate McCullough skilfully blends different filmic techniques into a formal experiment of fragmented pieces that involve old family videos by the grandfather, new video footage by Stephen, photographs, a recording of a documentary and of course the actual feature film itself. This fragmentation creates an uncertain reality for the audience as it is not entirely clear whether Stephen's story depicts the actual events or portrays what his mother tries to create as the truth. Pauses, flashbacks as well as fast-forwards are a constant reminder for the audience that reality is constructed, not absolute and up for interpretation.

25. Gerard Barrett, Glassland, Film, 2015.

26. Rebecca Daly, Mammal, Film, 2016. 
O'Hagan states that there is a counter reaction in Irish society against progressive feminist ideas that blame feminists as well as working mothers for social problems. ${ }^{27}$ As in Kaplan's description of the working mother, this counter reaction hints at social anxieties surrounding the contemporary liberalisation of the mother's place in the home and her progression into becoming an active member of the public sphere respectively. In Snap, the mother's need for day-care due to work commitments opens up the opportunity for the child's mistreatment by his grandfather. Society blames the working mother for her son's concerning behaviour and ultimately sanctions her by forcing her into isolation instead of the two male perpetrators of the film; Stephen as the kidnapper and his grandfather as sexual predator. Therefore, it is implied in Snap that the old value of the stay-athome mother could have prevented harm to the child.

In contrast to Kaplan's findings that motherhood, work and sex are not portrayed within one representation, Snap more or less combines the three aspects, even though they are based in a problematic narrative. Rosa GonzálezCasademont writes in Family and Dysfunction that sexuality is not usually represented in Irish film, unless it has negative connotations. ${ }^{28}$ In Snap, the regretting mother is indeed subjected to negative associations regarding sex in form of sexual assault and trauma. Sandra is only once shown to have sex when she sleeps with an older man whom she picks up at the fast food restaurant. Like all other sexual references, also this act is a reminder of the sexual assault by her father. In the scene, Sandra tries to keep in control demanding the older man to fully undress, to leave the light on and how to approach her. For a brief moment, Sandra allows the man to be embraced by her as he lies in her arm, but quickly feels disgusted by the physical closeness and throws him out of the apartment. The old man symbolises her father who sexually abused her in the past and over which she wishes to have power in order to escape her suppressed trauma.

Motherhood and sexuality do not exist harmoniously in Snap but collide with each other. Like sexuality is linked to trauma in Snap, it has "typically been linked to trauma, perversion, paedophilia, and social and political tension"29 in Irish film. Sexual abuse is indeed the source of the mother's blame by society as it lead to Stephen's idea of kidnapping a toddler. He uses the child to partially reenact non-sexual memories with his grandfather in the house, while watching old video tapes of the sexual assault in front of the toddler. Furthermore, the sexual encounter between Sandra and the man will be discovered by her repulsed son, creating more tension between the mother-son pair. Therefore, in Snap it is not the

27. Clare O'Hagan, Complex Inequalities and "Working Mothers" (Cork: Cork University Press, 2015), 13ff.

28. González-Casademont, "Representation of Family Tropes and Discourses in Contemporary Irish-Themed Cinema," 264.

29. Fintan Walsh, "Cock Tales: Homosexuality, Trauma and the Cosmopolitan Queer," Film Ireland 120, no. Jan./Feb. (2008), 16. 
mother's house that is the "cradle of evil," as Sandra calls it ironically, but sexuality is as the source of Sandra's and Stephen's trauma.

As mentioned, Sandra tries to gain control over her experience of sexual assault by re-enacting her own trauma as well as by participating in a documentary to tell her side of the kidnapping story. However, her attempt of gaining control ends in disappointment both times. She is unable to gain satisfaction by controlling the old man she sleeps with, and she realises that she ultimately has no control over the filmmaking process of the documentary.

This is especially visible when Sandra is supposed to re-record her formerly documented statements for the documentary. One of the filmmakers shows Sandra and her friend the footage on television to re-record the material. The footage is edited and shows a repeated shot of Sandra rubbing her hands between her legs in slow-motion, while talking about her son and father. She is shocked by her own words and the way the filmmakers edited her gestures, unknowingly hinting to her trauma. Sandra's inability to accept that she actually made certain statements in front of the camera and the realisation that it is impossible for her to create her own truth through the documentary makes her question the idea of setting the record straight via this approach. The fact that the documentary team consists of two men situates Sandra in a patriarchal power structure she wishes to escape as they have the final control over her voice. Therefore, despite Sandra's attempt to control the difficult situation of maternal blame by telling her side of the story, she is pushed back into an object position in which she is at the mercy of the male gaze. ${ }^{30}$

The imbalance between appearance and perception depicts an influential motif in Snap that effects Sandra's misjudgements. Her ability to detach herself from her own past and inability to recognise herself in pictures or camera recordings underline the suppressed experiences. Because of the associated memory loss, she was able to give her son to her abusive father, suppressing the idea that he could also abuse a male child. The working mother is unable to see the tension between her own father and Stephen due to her own emotionally suppressive behaviour in regards to her traumatic experiences. In Snap, this leads to her emotional and physical rejection of her son as well as her regret to be a mother in general. Like Rozsika Parker explains in the context of maternal ambivalence, some mothers are reminded of their own childhood by interacting with their children. Therefore, spending time with their children depicts a struggle for those who do not want to re-live a trauma. ${ }^{31}$ Sandra's avoidance of Stephen as well as her inability to recognise herself in pictures and recordings serve Sandra in order to suppress her sexually abusive past and prevent her from

30. Eileen Leahy, "Snap (Carmel Winters, 2010)," Estudios Irlandeses - Journal of Irish Studies 6 (2011).

31. Rozsika Parker, Torn in Two. The Experience of Maternal Ambivalence (Revised Ed. London: Virago Press, 2005), 209. 
having to deal with her memories.

Filming the documentary, she voices her regret of becoming a mother instead of a nun. In this monologue, she reveals that her identity circles around the Catholic ideals of womanhood - motherhood and being a nun.

Sandra I wasn't cut out to be a mother. Nothing personal, just... . You know what I wanted to be when I was a kid? A nun. You could see me, couldn't you? Swanning around in the bin-bag dress. Big fuck off cross guarding my tits.

Sandra expresses her childhood wish rather self-mockingly. While the camera zooms in on her eyes, she contemplates the just said before revising her words from "tits" to "chest" in order to sound more adapted to the audience's expectations. Sandra's wish to be a nun instead of a mother represents the Catholic binary roles of spiritual versus biological motherhood for women. An individuality outside of motherhood is not respected and does not seem to cross Sandra's mind in Snap. Her wish to be a nun, however, seems less of a fulfillment of her individual desires rather than a shelter from her sexually abusive past. The cross that guards her chest stands symbolically for the possibility of defending herself against her abuser, while the close-up on her eyes tell the audience that she believes to be incapable of this defense. Sandra's symbolic position within a patriarchal power structure of a Church that is infamous for its child abuse scandals in Ireland ${ }^{32}$ and a sexually abusive family make it impossible to attribute her the chaste individuality that would have come with being a nun, rendering this imagined scenario unreachable.

Sandra herself is portrayed within the realms of traditional Irish female roles that are strongly connected with nationalism and the Catholic Church. By withholding the revelation of a certain father figure, the reference to a possible virgin birth in Snap fits within the portrayal of the Irish mother which embodies motherhood and virginity at the same time, embracing a Catholic ideal of womanhood. However, while Snap refers to this stereotypical representation of the mother in Irish film that is mostly represented in transnational productions, Snap offers a more complex portrayal of the regretting mother. Sandra's rather harsh appearance refuses to fully mirror this maternal ideal that has an altruistic woman at its core. To a greater degree, Sandra's selfjustifying attempt to rewrite her family's public reception as well as her hostile appearance embodies the idea of the feisty Irish woman - known from figures such as Mary Kate Danaher (Maureen O'Hara) in the movie The Quiet Man. ${ }^{33}$

32. Diarmaid Ferriter, Occasions of Sin and Society in Modern Ireland (London: Profile Books, 2009), 447.

33. John Ford, The Quiet Man, Film, 1952. 
In this way, Snap can be found to flesh out the strong female characters of Irish cinema, with an intimation that Sandra's defensive aggression results from a past trauma. Her shades of the stereotypical feisty Irish colleen also suggest cinema's ambivalent relationship to such characters, fetishizing "the strong female while simultaneously working to undermine her." 34,35

Sandra represents a strong female character who continuously tries to make herself heard. However, her side of the story is undermined through the reaction of society, the fragmentation of footage as well as her inability to remember her own past.

Therefore, Sandra's wish not to mother is equally ignored by the people around her. As Sandra believes that motherhood is not her vocation, her deepest regret is that she actually had a child in the first place. She does not enjoy the contact with her son as she struggles to maintain any physical or emotional closeness to him, nor does she seem to regret giving up her first-born daughter. As Donath describes, it is important to divert from the idea that mothers always have a choice whether they want to mother, and to focus on their "'will,' 'desire,' 'orientation' and 'consent'" towards motherhood. ${ }^{36}$ In Snap, Sandra clearly expresses her will not to mother. However, as she was more than likely forced to have sex with her own father without consent, she involuntarily became pregnant twice. While she gave her daughter for adoption, she decided to keep her son, regretting her decision later. Therefore, Sandra's subjective ideal lies in nonmotherhood, while the social order of a patriarchal society takes the woman's agency over her own body, forcing her into motherhood.

While Sandra is forced to mother in a patriarchal society, she struggles to fit into the concept of, what Ahmed denotes, "respectable femininity" which is associated with the "capacity to touch and be touched by others." 37 The continuous motif of hands that do not want to be touched or touch another person symbolise a disconnection between mother and son, but also between grandfather and son as well as grandfather and mother. The gesture of the hands, mostly shown in close-ups, reveals the suppressed problematic past to the audience even before the abuse by the grandfather on daughter and grandson is revealed. The fact that Sandra is not capable of touching her son, without feeling repulsed, disconnects the idea of unquestioned maternal care from the regretting mother. In order to survive, Sandra has to suppress her trauma and keep her distant from her son. This behaviour stands outside of the popular societal ideal

34. Barton, "Maureen O’Hara: Pirate Queen, Feminist Icon?" Éire-Ireland 41, no. 1\&2 (2006), 145.

35. Leahy, "Snap (Carmel Winters, 2010).

36. Orna Donath, "Choosing Motherhood? Agency and Regret within Reproduction and Mothering Retrospective Accounts," Women's Studies International Forum 53 (2015), 201.

37. Sara Ahmed, The Cultural Politics of Emotion (Edinburgh: Edinburgh University Press, 2004), 124. 
of an altruistic, caring mother which is why Sandra is blamed for her son's misbehaviour and positions her outside of a "respectable femininity" in Snap.

The reinforcement of patriarchal power structures by Irish society pushes the regretting mother into a maternal role she does not want to embrace. Society only blames the mother for Stephen's behaviour and, therefore, for her misjudgement to give Stephen into his grandfather's care. This stands in line with Rozsika Parker's description that "the dominant cultural belief is that mothers do indeed entirely determine the personality of their children. 'Mother blaming' is a symptom of the power vested in mother" ${ }^{38}$ by, in this case, Irish society and the lingering teachings of the Catholic Church. Neither does the actual abuser receive any blame in Snap, nor does society blame the sexual predator for forcing Sandra into motherhood in the first place. Sandra's maternal regret, that is magnified through her position as scapegoat in the public eye, is rooted in the abuse she experienced as a child rather than the overwhelming experience of maternal responsibilities.

The accepted understanding of womanhood by society portrayed in Snap does include caring women who want to mother but does exclude a regretting mother who admits her negative feelings towards her children openly. While Sandra does not seem to regret giving up her daughter - this may be because she did not want to mother a female child, or because of the possible threat of sexual abuse by her father -, she is aware that other people do not understand her rejection of the child. At the same time, Sandra knows about the advantage she can gain as a mother, pretending she misses her daughter.

Sandra You know the funniest thing? They loved me when they thought it was me who did it. They fucking idolised me. "In your own time, Sandra. In your own words." Anyone would think I was the long lost child. Poor old ban-garda was in floods. I fed her all about the kid I had to give up, how the kid in the park reminded me of it.

Sandra claims in front of the police that she had to give up the child, implying that this was against her will. The audience, however, later learns that it was Sandra's decision not to mother her daughter. Recording the documentary, Sandra mocks the fact that society meets a mother who kidnaps a child in order to give maternal care with understanding but blames a mother who did not actually do the crime.

This blame reinforces the regretting mother to stay within the sphere of the home instead of allowing her to break out of the forced role of motherhood. This re-enforcement of the private over the public stays in line with the treatment of non-traditional mothers in Ireland. Historically in Ireland, single motherhood was made the focal issue over sexual misconduct by men and priests. Single mothers

38. Parker, Torn in Two, 259. 
were blamed for sexual activities and contained within religious institutions, such as the Magdalene Laundries. ${ }^{39}$ In Snap, Sandra is blamed for her father's misconduct and her confinement to the impersonally furnished apartment represents Ireland's containment culture and the recent practice of institutionalisation. Within the domestic sphere in-between spaces of the house, such as balcony and hallway, become a way to express her frustration over this confinement and over the societal pressure into a role she does not want to fulfil. In order to resist against the maternal blame, Sandra aggressively throws unwanted items, such as burned hate mail or alcohol that threatens her abstinence as an alcoholic, into these half-public spaces. As described in this article, Sandra struggles with the domestic but also with the public sphere, as she is forced by society to stay within the former, while receiving blame in the latter.

Historically, the role of the father in Irish cinema is reduced to a nonpowerful, abusive figure. As McLoone notes "very often [...] the crisis of identity faced by the young protagonist is exacerbated by the fact that one of the parents is missing and, in the case of the father, is either dead or hopelessly ineffectual." 40 This common ineffectiveness in the representation of the father developed due to the disempowerment of the Irish through the colonization by the English as well as later the symbolical removal of the father as head of the family by the priest as new authoritative entity. ${ }^{41}$

As mentioned, it is suggested that Sandra's father could also be the father of Stephen. The only suggested alternative father figure for Stephen could be a random man Sandra picked up for a one-night-stand, just like the man from the fast food shop. However, Stephen's grandfather remains the only paternal figure present in Stephen's life. His role, however, is more complicated than merely a representation of the disempowered, ineffectual Irish male. Even though his actual time on screen is limited as well as characterised by a weak physique due to his hospitalisation, his influence on Sandra and Stephen through the induced trauma is crucial to their behaviour. Therefore, he rather represents the patriarchal power structure that is upheld by the Catholic Church as well as the ongoing sexual abuse within Catholic institutions. As . explains in Estudio Irlandeses about the role of Stephen's grandfather:

...his status as patriarch in the film, reconfigures this Catholic idea by invoking the essential "incestuous edge" of oedipal conflicts at the heart of Irish national identity. [Snap] engages the familiar tropes of Irish dysfunctional families, child

39. James M. Smith, "The Politics of Sexual Knowledge: The Origins of Ireland's Containment Culture and the Carrigan Report (1931)," Journal of History of Sexuality 13, no. 2 (2004), 221.

40. McLoone, Irish Film, 174.

41. González-Casademont, "Representation of Family Tropes, 260. 
abuse and the malign pervasiveness of the past through our present life. ${ }^{42}$

This coming to terms with the past is significant to understand the role of the father in Snap and needs to be taken into account when creating a new categorisation of regretting motherhood in addition with Kaplan's groundwork on the absent mother. The fact that Sandra is working makes her a temporarily absent mother in accordance with Kaplan's categorisation who gives the responsibility of caring to her father. Sandra's emotional and partially physical absence as mother as well as her father's behaviour, however, divert from Kaplan's categorisation. While Kaplan introduces the concept of the nurturing father as a result of an absent mother, Sandra's refusal to mother does not lead to the representation of a caring father. Instead the parental figure exploits the child by sexually molesting Stephen. Furthermore, unlike in American film, Sandra never regrets her maternal absence as she suppresses the knowledge of the previous sexual assault as well as the idea that her father could do the same with her male child. In contrast to American film, in this Irish film the partially physical and emotional absent mother is not located within the genre of comedy which allows the father to explore his new parenting role. Instead the narrative is situated within a dark psychological drama that explores the trauma of sexual assault inflicted by mostly Catholic institutions in Irelands recent past.

\section{Conclusion}

While Kaplan's seminal categorisation of motherhood offers a valuable starting point to analyse newly emerging maternal characters in Irish film, a more comprehensive observation of these new categorise are of importance. Therefore, this article proposed the complex maternal characters of Carmel Winters' films as basis of an exploration of the woman who wants to be a mother and the regretting mother as new categorisations in contemporary Irish film.

The woman who wants to be a mother in Limbo manifests anxieties that had arisen in Ireland with the recession of 2008. New values of sexually liberal and working women were questioned and old values of motherhood reintroduced to the urban sphere of Dublin. This trend mirrors the anxieties and ensuing representations of the desirability of the domestic Kaplan describes in relation to the working mother in American film. Limbo represents this tension between the private and the public via the baby changing room and the private atmosphere in the public park St. Stephen's Green. Both spaces as well as the woman's pseudopregnancy situate the woman who wants to be a mother within a liminal space that resembles the concept of limbo - the films title. The inanimateness of the chicken, which functions as substitute foetus,

42. Leahy, "Snap (Carmel Winters, 2010). 
hints towards the possibility of infertility and turns the maternal representation into a grotesque version of a pregnancy that questions the desirability of motherhood for urban women. As the representation of women living in Dublin focused on their sexuality instead of their maternal identity in the previous decade, also the urban woman who wants to be a mother in Limbo is still somewhat detached from motherhood. While the influence of the Catholic Church in Ireland declined, traditional influences are still represented within the maternal characters of both films discussed in this article. The maternal ideal of a virgin birth is implied in Limbo and situates the mother within a long tradition of maternal representations in Irish film.

The regretting mother in Snap negotiates maternal ideals and reality. While the working mother in Kaplan's description easily combines motherhood and work, the regretting mother in Snap struggles with this combination. While work for the working mother is desirable, work for Sandra is a financial necessity and one of the reasons why she supposedly failed in her role. Due to her work commitments Sandra is forced to give her child into the care of her father which makes her a temporarily absent mother in line with Kaplan's categorisation. However, the regretting mother neither regrets her absence, nor does the substitutional father figure gain the sympathy of the audience. He rather abuses the child and represents Ireland's dark history of sexual abuse in the family and by Catholic institutions. Like in other Irish films that focus on regretting mothers, such as Glassland and Mammal, Snap is a dark psychological drama that negotiates a trauma of the Irish nation - in this case sexual abuse. The sexual trauma leads to the regretting mother's suppression of the past, her inability to emotionally connect to her son, and her maternal regret is ultimately rooted in the abuse rather than in unwanted maternal responsibilities. Therefore, in Snap sexuality is represented negatively like in many other Irish films. Sandra repeatedly tries to gain control over her situation. However, her positioning within a patriarchal society that blames the mother for her son's misbehaviours makes it impossible to attribute her any agency. She stands outside the respected definition of femininity that is able to give love to others and is, therefore, blamed by society which ultimately confines her to the domestic sphere. As in Limbo, in Snap, the regretting mother embodies a tension between the private and the public, mirroring anxieties around changing gender roles and re-negotiating the country's values in an urban setting. She portrays aspects of the feisty Irish colleen who tries to take control over her own story but will ultimately realise the importance of reflecting on the self instead. The use of fragmented footage as well as the control by the male narrator of the documentary pieces and old home-movie footage makes it difficult to fully attribute Sandra her own voice. Reality becomes uncertain and the mother's identity struggles between her own perception of the events and their actual appearance on the screen ultimately controlled by men. She understands womanhood merely within the binary understanding of the Catholic Church in which either motherhood or being a nun are acceptable options. 
Sandra, however, never seemed to be in charge of this binary choice and is forced into motherhood by a patriarchal society in Snap.

The two new categories of motherhood explored in this article - the woman who wants to be a mother and the regretting mother - show the necessity of adapting Kaplan's categorisation to an Irish context. The intersectionality of the groupings remains important as categories often overlap. For example, the regretting mother in Snap incorporates aspects of the absent as well as the working mother. Further research, involving films outside of Winters' corpus, will be important in the future to broaden the definition of these two categories of motherhood in Irish film to gain a deeper understanding of these two newly emerging categorisations in line with Kaplan's original groundwork.

\section{Acknowledgments}

My thanks goes to Dr. Denis Condon and Dr. Valerie Heffernan for their continuous support of my $\mathrm{PhD}$ research, including this article, for their knowledge, patience and motivation.

\section{Funding}

This research is funded by the Irish Research Council.

\section{Bibliography}

Ahmed, Sara. The Cultural Politics of Emotion. Edinburgh: Edinburgh University Press, 2004.

Barrett, Gerard. Glassland. Film, 2015.

Barton, Ruth. "Maureen O'Hara: Pirate Queen, Feminist Icon?" Éire-Ireland 41, no. $1 \& 2$ (2006), 142-168.

_. Irish National Cinema. London and New York: Routledge, 2004.

Berendsen, Dan. Baby Daddy. TV Series, 2012-2017.

Chodorow, Nancy J. The Reproduction of Mothering. Los Angeles: University of California Press, 1978.

Daly, Rebecca. Mammal. Film, 2016.

Donath, Orna. "Choosing Motherhood? Agency and Regret within Reproduction and Mothering Retrospective Accounts." Women's Studies International Forum 53 (2015), 200-209.

Dublin: 4DayMovie 2008. Retrieved from https://4daymovie.wordpress.com. Accessed: March 2018. 
Ferriter, Diarmaid. Occasions of Sin and Society in Modern Ireland. London: Profile Books, 2009.

Ford, John. The Quiet Man. Film, 1952.

Franklin, Jeff. Full House. TV Series, 1987-1995.

Gill, Elizabeth. Goldfish Memory. Film, 2003.

Gillespie, Michael Patrick. The Myth of an Irish Cinema - Approaching Irish-Themed Films. Syracuse, New York: Syracuse University Press, 2008.

González-Casademont, Rosa. "Representation of Family Tropes and Discourses in Contemporary Irish-Themed Cinema." In Family and Dysfunction in Contemporary Irish Narrative and Film, edited by Marisol Morales-Ladrón, 233300. Bern: Peter Lang, 2016.

Holohan, Conn. "The Short Film and Irish Cinema." Estudio Irlandeses 4 (2009), 184-186.

Kaplan, E. Ann. Motherhood and Representation: The Mother in Popular Culture and Melodrama. London: Routledge, 1992.

_. "Sex, Work and Motherhood: The Impossible Triangle." The Journal of Sex Research 27, no. 3 (1990), 409-425.

Leahy, Eileen. "Snap (Carmel Winters, 2010)." Estudios Irlandeses - Journal of Irish Studies 6 (2011).

McLoone, Martin. Irish Film. The Emergence of Contemporary Cinema. London: British Film Institute, 2000.

O'Hagan, Clare. Complex Inequalities and "Working Mothers". Cork: Cork University Press, 2015.

Parker, Rozsika. Torn in Two. The Experience of Maternal Ambivalence. Revised Edition, London: Virago Press, 2005.

Shyer, Charles. Baby Boom. Film, 1987.

Smith, James M. "The Politics of Sexual Knowledge: The Origins of Ireland's Containment Culture and the Carrigan Report (1931)." Journal of History of Sexuality 13, no. 2 (2004), 208-233.

Walsh, Fintan. "Cock Tales: Homosexuality, Trauma and the Cosmopolitan Queer." Film Ireland 120, no. Jan./Feb. (2008), 16-17.

Winters, Carmel. Limbo. Film, 2008.

_. Snap. Film, 2010. 
